
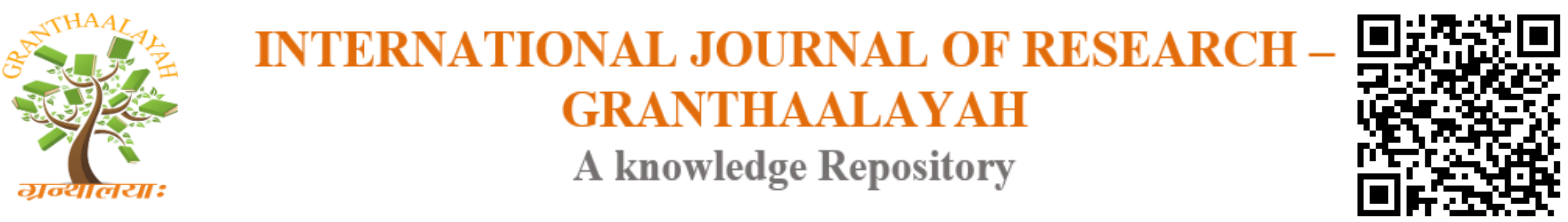

Science

\title{
DECREASING ACTUAL POWER LOSS BY REFINED ABC ALGORITHM
}

\author{
Dr.K.Lenin *1 \\ ${ }^{* 1}$ Professor, Department of EEE Prasad V.Potluri Siddhartha Institute of Technology, Kanuru, \\ Vijayawada, Andhra Pradesh -520007, India
}

\begin{abstract}
Refined $\mathrm{ABC}$ algorithm (RABC) proposed in this paper to solve the optimal reactive power problem. An artificial bee colony (ABC) algorithm is one of copious swarm intelligence algorithms that employ the foraging behavior of honeybee colonies. To progress the convergence performance and search speed of finding the best solution RABC algorithm has been developed. The main objective in this problem is to minimize the real power loss and also to keep the variables within the specified limits. Proposed Refined ABC (RABC) algorithm has been tested in standard IEEE 118 \& practical 191 bus test systems and simulations results reveal about the better performance of the proposed Refined ABC algorithm (RABC) algorithm in reducing the real power loss and the voltage profiles within the limits.
\end{abstract}

Keywords: Refined ABC Algorithm; Swarm Intelligence; Optimal Reactive Power; Transmission Loss.

Cite This Article: Dr.K.Lenin. (2017). "DECREASING ACTUAL POWER LOSS BY REFINED ABC ALGORITHM." International Journal of Research - Granthaalayah, 5(10), 63-71. https://doi.org/10.29121/granthaalayah.v5.i10.2017.2269.

\section{Introduction}

Optimal reactive power problem plays most important role in the stability of power system operation and control. In this paper the main aspect is to diminish the real power loss and to keep the voltage variables within the limits. Previously many mathematical techniques like gradient method, Newton method, linear programming [4-7] has been utilized to solve the optimal reactive power dispatch problem and those methods have many difficulties in handling inequality constraints. Voltage stability and voltage collapse play an imperative role in power system planning and operation [8]. Recently Evolutionary algorithms like genetic algorithm have been already utilized to solve the reactive power flow problem [9,10].In [11-20] Genetic algorithm, Hybrid differential evolution algorithm, Biogeography Based algorithm, fuzzy based methodology, improved evolutionary programming has been used to solve optimal reactive power flow problem and all the algorithm successfully handled the reactive power problem. The Artificial Bee Colony (ABC) algorithm was introduced by Karaboga [21] as a technical report, then its performance was measured using benchmark optimization functions [22,23]. A recent 
study [24] showed that ABC algorithm performs significantly better or at least comparable to other SI algorithms as genetic algorithm [25], DE, and PSO algorithms. The ABC algorithm has been applied to several fields in various ways, for example, training neural networks [26]; solving sensor deployment problem[27]; applied for engineering design optimization [28].The $\mathrm{ABC}$ algorithm is superior to other algorithms in terms of its simplicity, flexibility and robustness. In addition, the $\mathrm{ABC}$ algorithm requires fewer training parameters; so combining it with other algorithms is easier. The standard $\mathrm{ABC}$ algorithm was based on the results of some standard benchmark problems, however, as an initial proposal; it still has a considerable performance gap with respect to state-of the- art algorithms. In particular, it was found to have relatively poor performance on composite and non-separable functions, and have a slow convergence rate toward high quality solutions. To improve the performance, the ABC algorithm has been extended in a number of ways recently. For example, Alatas [29] proposed a chaotic $\mathrm{ABC}$ algorithm, in which many chaotic maps for parameters adapted from the original ABC were introduced to improve its convergence performance; Zhu and Kwong [30] proposed a global best (Gbest) guided $\mathrm{ABC}$ algorithm by incorporating the information of global best solution into the solution search equation to improve the exploitation; Banharnsakun et al. [31] introduced best-so-far selection to standard ABC algorithm; Karaboga and Gorkemli [32] introduced a combinatorial ABC for travelling salesman problems. In addition, Gao and Liu [33] proposed a modified $\mathrm{ABC}$ algorithm (MABC) that used a modified solution search equation with chaotic initialization, which excluded the probabilistic selection scheme and scout bees phases. Along with the advantages of the improved versions of $\mathrm{ABC}$, however, a few disadvantages still exist. For example, ABC algorithms have low convergence speeds, low exploitation abilities, and are also easily trapped in local optima. To overcome these disadvantages, we focus on the predominance of hybridizing other algorithms easily and propose a Refined ABC algorithm, which inspired by self-adaptive mechanism, incorporated DE (Differential evolution) and PSO (Particle swarm optimization) algorithms. Proposed Refined ABC (RABC) algorithm has been tested in standard IEEE 118 \& practical 191 bus test systems and simulations results reveal about the better performance of the proposed Refined ABC algorithm (RABC) algorithm in reducing the real power loss and the voltage profiles within the limits.

\section{Objective Function}

\subsection{Active Power Loss}

The objective of the reactive power dispatch problem is to minimize the active power loss and can be defined in equations as follows:

$\mathrm{F}=\mathrm{PL}=\sum_{\mathrm{k} \in \mathrm{Nbr}} \mathrm{g}_{\mathrm{k}}\left(\mathrm{V}_{\mathrm{i}}^{2}+\mathrm{V}_{\mathrm{j}}^{2}-2 \mathrm{~V}_{\mathrm{i}} \mathrm{V}_{\mathrm{j}} \cos \theta_{\mathrm{ij}}\right)$

Where $g_{k}$ : is the conductance of branch between nodes $\mathrm{i}$ and $\mathrm{j}$, Nbr: is the total number of transmission lines in power systems.

\subsection{Voltage Profile Improvement}

To minimize the voltage deviation in PQ buses, the objective function can be written as: 
$\mathrm{F}=\mathrm{PL}+\omega_{\mathrm{v}} \times \mathrm{VD}$

Where $\omega_{\mathrm{v}}$ : is a weighting factor of voltage deviation.

VD is the voltage deviation given by:

$\mathrm{VD}=\sum_{\mathrm{i}=1}^{\mathrm{Npq}}\left|\mathrm{V}_{\mathrm{i}}-1\right|$

\subsection{Equality Constraint}

The equality constraint of the problem is indicated by the power balance equation as follows:

$P_{G}=P_{D}+P_{L}$

Where the total power generation PG has to cover the total power demand PD and the power losses PL.

\subsection{Inequality Constraints}

The inequality constraint implies the limits on components in the power system in addition to the limits created to make sure system security. Upper and lower bounds on the active power of slack bus, and reactive power of generators are written as follows:

$\mathrm{P}_{\text {gslack }}^{\min } \leq \mathrm{P}_{\text {gslack }} \leq \mathrm{P}_{\text {gslack }}^{\max }$

$\mathrm{Q}_{\mathrm{gi}}^{\min } \leq \mathrm{Q}_{\mathrm{gi}} \leq \mathrm{Q}_{\mathrm{gi}}^{\max }, \mathrm{i} \in \mathrm{N}_{\mathrm{g}}$

Upper and lower bounds on the bus voltage magnitudes:

$\mathrm{V}_{\mathrm{i}}^{\min } \leq \mathrm{V}_{\mathrm{i}} \leq \mathrm{V}_{\mathrm{i}}^{\max }, \mathrm{i} \in \mathrm{N}$

Upper and lower bounds on the transformers tap ratios:

$\mathrm{T}_{\mathrm{i}}^{\min } \leq \mathrm{T}_{\mathrm{i}} \leq \mathrm{T}_{\mathrm{i}}^{\max }, \mathrm{i} \in \mathrm{N}_{\mathrm{T}}$

Upper and lower bounds on the compensators

$\mathrm{Q}_{\mathrm{c}}^{\min } \leq \mathrm{Q}_{\mathrm{c}} \leq \mathrm{Q}_{\mathrm{C}}^{\max }, \mathrm{i} \in \mathrm{N}_{\mathrm{C}}$

Where $\mathrm{N}$ is the total number of buses, NT is the total number of Transformers; Nc is the total number of shunt reactive compensators. 


\section{Standard ABC Algorithm}

In the $\mathrm{ABC}$ algorithm, the artificial bee colony comprises three kinds of bees: employed bees, onlooker bees, and scout bees. Employed bees search for food source sites by modifying the site in their memory, evaluating the nectar amount of each new source, and memorizing the more productive site through a selection process. These bees share information related to the quality of the food sources they exploit in the "dance area". The number of employed bees is equal to the number of food sources for the hive. Onlooker bees search for food sources based on the information coming from employed bees within the hive. As such, more beneficial sources have higher probability to be selected by onlookers. Further, onlooker bees choose food sources depending on the given information through probabilistic selection and modify these sources. When the food source is abandoned, a new food source is randomly selected by a scout bee to replace the abandoned source. The number of food sources in ABC algorithm is equivalent to the number of solutions in a population for an optimization problem. The number of nectar sites of a food source represents the fitness cost of the associated solution.

The main steps of the standard $\mathrm{ABC}$ algorithm are given below:

1. Initialize the population of solutions $x_{i j}$ with

$$
x_{i j}=x_{\min , j}+\operatorname{rand}[0,1]\left(x_{\max , j}-x_{\min , j}\right)
$$

Where, $i \in 1,2, \ldots, S N$ and $j \in 1,2, \ldots, D$ are randomly selected indexes, $S N$ is the number of food source, and $D$ is the dimension size.

2. Evaluate the population.

3. Initialize cycle to 1.

4. Produce new solutions $v_{i}$ for the employed bees by using (10), then evaluate them as follows

$v_{i j}=x_{i j}+\phi_{i j}\left(x_{i j}-x_{k j}\right)$

where $\phi_{i j}$ is a uniformly distributed random number in the range $[-1,1] ; i, k \in 1,2, \ldots, S N$ are randomly selected indexes with $k$ different from $i$ and $j \in 1,2, \ldots, D$ is a randomly selected index.

5. Apply the greedy selection process for the employed bees.

6. If the solution does not improve, add 1 to the trail, otherwise, set the trail to 0 .

7. Calculate probability values $P_{i}$ for the solutions using (12) as

$P_{i}=\frac{\text { fit }_{i}}{\sum_{n=1}^{S N} f i t_{n}}$

Where fit $_{i}$ is the fitness value of solution $i$.

8. Produce new solutions for the onlooker bees from solutions $x_{i}$, which is selected depending on $p_{i}$, then evaluate them.

9. Apply the greedy selection process for the onlooker bees.

10. If the solution does not improve, add 1 to the trail, otherwise, set the trail to 0.

11. Determine the abandoned solution for the scout, if it exists, and replace it with a new random solution using (10).

12. Memories the best solution achieved so far.

13. Add 1 to cycle.

14. Repeat until cycle reaches a predefined maximum cycle number $(M C N)$. 


\section{Refined ABC Algorithm (RABC)}

There are two common aspects in population based heuristic algorithms, i.e., exploration and exploitation. Exploration is the ability to expand the search space, and exploitation is the ability to find optima around a good solution. Exploration and exploitation play key roles in SI algorithms. They coexist in the evolutionary process of algorithms such as PSO, DE, and ABC, but they contradict each other. To achieve a good optimization performance with higher convergence speeds and not trapped in local optima, a self adaptive mechanism to change the search range related with a cycle number was introduced, and then combined with DE to improve the performance of the employed bees. In the standard ABC algorithm, a random perturbation is added to the current solution to produce a new solution. This random perturbation is weighted by $\phi_{i j}$ selected from $[-1,1]$ and is an uniformly distributed real random number in the standard ABC. Too large or too small value of $\phi_{i j}$ affects the convergence speed. Therefore, a self-adaptive mechanism is used to balance the convergence speed and the exploration ability of the algorithm for employed bees. The self adaptive mechanism of ABC consists of very simple structure and is easy to implement. The $\phi_{i j}$ is changed with the cycle number according to a random value called rand in the range $[0,1]$ for the food searching process of an employed bee; $\phi_{i j}$ is determined as (13).

$\emptyset_{i}= \begin{cases}-e^{-3 * \frac{c y c l e}{(25 * M C N)}} & 0 \leq \text { rand } \leq 0.5 \\ -e^{-3 * \frac{c y c l e}{(25 * M C N)}} & 0.5 \leq \text { rand } \leq 1\end{cases}$

The searching food source process in the standard $\mathrm{ABC}$ algorithm is similar to the mutation process of DE. Besides, in DE [34, 35], the best solution in the current population is very advantageous for higher convergence performance. As one scheme of the mutations of DE, "DE/best/1" can effectively maintain population diversity. The "DE/best/1" mutation strategy was combined with the food search process of the standard ABC algorithm to produce a new search equation (14) and improved the convergence ability.

$v_{i j}=x_{\text {best }, j}+\phi_{i j}\left(x_{i j}-x_{k j}\right)$

Where $i, k \in 1,2, \ldots, S N$ are randomly selected indexes with $k$ different from $i ; j \in 1,2, \ldots, D$ is a randomly selected index and $\phi_{i j}$ is the parameter given in (13).

It was determined that the search ability of the $\mathrm{ABC}$ algorithm is good at exploration, but poor in terms of exploitation. Specifically, the relationship of employed bees and onlooker bees are focused on exploration and exploitation, respectively. Employed bees explore new food sources and send information to onlooker bees, and onlooker bees exploit the food sources explored by employed bees. In the standard $\mathrm{ABC}$ algorithm, much time is required to find the food source due to poor exploitation abilities and lower convergence speeds. To improve the exploitation ability and convergence performance of the algorithm, we incorporated PSO [36] into the standard ABC algorithm. PSO is based on the simulation of simplified social animal behaviors and it has the advantage of good convergence performance. We modified the onlooker bee search solution by taking advantage of the search mechanism of PSO; our modified search equation for onlooker bees is shown as (15).

$v_{i j}=x_{i j}+\varphi_{i j}\left(x_{i j}-x_{k j}\right)+\psi_{i j}\left(x_{b e s t, j}-x_{i j}\right)$ 
Where $i, k \in 1,2, \ldots, S N$ are randomly selected indexes with $k$ different from $i ; j \in 1,2, \ldots, S N$ is a randomly selected index; $x_{\text {best }, j}$ is the $j$-th element of the best dominant solution, and $\varphi_{i j} \in[-1,1]$ and $\psi_{i j} \in[0,1.2]$ are uniformly distributed random numbers. The proposed Refined ABC algorithm (RABC) modifies the standard $\mathrm{ABC}$ in step $4 \& 8$. The modification (4) and (5) are introduced to substitute (2) on step 4; the modification (6) is introduced to substitute (2) on step 8 .

\section{Simulation Results}

At first Refined ABC algorithm (RABC) has been tested in standard IEEE 118-bus test system [37].The system has 54 generator buses, 64 load buses, 186 branches and 9 of them are with the tap setting transformers. The limits of voltage on generator buses are $0.95-1.1$ per-unit., and on load buses are $0.95-1.05$ per-unit. The limit of transformer rate is $0.9-1.1$, with the changes step of 0.025 . The limitations of reactive power source are listed in Table 1, with the change in step of 0.01 .

Table 1: Limitation of reactive power sources

\begin{tabular}{|l|l|l|l|l|l|l|l|}
\hline BUS & 5 & 34 & 37 & 44 & 45 & 46 & 48 \\
\hline QCMAX & 0 & 14 & 0 & 10 & 10 & 10 & 15 \\
\hline QCMIN & -40 & 0 & -25 & 0 & 0 & 0 & 0 \\
\hline BUS & 74 & 79 & 82 & 83 & 105 & 107 & 110 \\
\hline QCMAX & 12 & 20 & 20 & 10 & 20 & 6 & 6 \\
\hline QCMIN & 0 & 0 & 0 & 0 & 0 & 0 & 0 \\
\hline
\end{tabular}

The statistical comparison results of 50 trial runs have been list in Table 2 and the results clearly show the better performance of proposed RABC algorithm.

Table 2: Comparison results

\begin{tabular}{|l|l|l|l|l|}
\hline Active power loss (p.u) & $\begin{array}{l}\text { BBO } \\
{[38]}\end{array}$ & $\begin{array}{l}\text { ILSBBO/ } \\
\text { strategy1 } \\
{[\mathbf{3 8}]}\end{array}$ & $\begin{array}{l}\text { ILSBBO/ } \\
\text { strategy1 } \\
{[\mathbf{3 8}]}\end{array}$ & $\begin{array}{l}\text { Proposed } \\
\text { RABC }\end{array}$ \\
\hline Min & 128.77 & 126.98 & 124.78 & 116.76 \\
\hline Max & 132.64 & 137.34 & 132.39 & 121.82 \\
\hline Average & 130.21 & 130.37 & 129.22 & 118.48 \\
\hline
\end{tabular}

Then the Refined ABC algorithm (RABC) has been tested in practical 191 test system and the following results have been obtained. In Practical 191 test bus system - Number of Generators = 20 , Number of lines $=200$, Number of buses $=191$ Number of transmission lines $=55$. Table 3 shows the optimal control values of practical 191 test system obtained by RABC method. And table 4 shows the results about the value of the real power loss by obtained by Refined $A B C$ algorithm (RABC).

Table 3. Optimal Control values of Practical 191 utility (Indian) system by RABC method

\begin{tabular}{l|l|l|l|l}
\hline VG1 & 1.10 & \multirow{5}{*}{} & VG 11 & 0.90 \\
VG 2 & 0.72 & VG 12 & 1.00 \\
VG 3 & 1.01 & & VG 13 & 1.00 \\
\hline
\end{tabular}




\begin{tabular}{l|l|l|l|l}
\hline VG 4 & 1.01 & & VG 14 & 0.90 \\
\cline { 1 - 1 } VG 5 & 1.10 & VG 15 & 1.00 \\
\hline VG 6 & 1.10 & & VG 16 & 1.00 \\
\hline VG 7 & 1.10 & VG 17 & 0.90 \\
\hline VG 8 & 1.01 & VG 18 & 1.00 \\
\hline VG 9 & 1.10 & VG 19 & 1.10 \\
\hline VG 10 & 1.01 & VG 20 & 1.10 \\
\hline
\end{tabular}

\begin{tabular}{|c|c|c|c|c|c|}
\hline $\mathrm{T} 1$ & 1.00 & $\mathrm{~T} 21$ & 0.90 & T41 & 0.90 \\
\hline $\mathrm{T} 2$ & 1.00 & $\mathrm{~T} 22$ & 0.90 & T42 & 0.90 \\
\hline T3 & 1.00 & $\mathrm{~T} 23$ & 0.90 & T43 & 0.91 \\
\hline T4 & 1.10 & $\mathrm{~T} 24$ & 0.90 & T44 & 0.91 \\
\hline $\mathrm{T} 5$ & 1.00 & $\mathrm{~T} 25$ & 0.90 & $\mathrm{~T} 45$ & 0.91 \\
\hline T6 & 1.00 & T26 & 1.00 & T46 & 0.90 \\
\hline T7 & 1.00 & $\mathrm{~T} 27$ & 0.90 & T47 & 0.91 \\
\hline T8 & 1.01 & $\mathrm{~T} 28$ & 0.90 & T48 & 1.00 \\
\hline T9 & 1.00 & $\mathrm{~T} 29$ & 1.01 & T49 & 0.90 \\
\hline T10 & 1.00 & $\mathrm{~T} 30$ & 0.90 & T50 & 0.90 \\
\hline T11 & 0.90 & $\mathrm{~T} 31$ & 0.90 & T51 & 0.90 \\
\hline $\mathrm{T} 12$ & 1.00 & T32 & 0.90 & T52 & 0.90 \\
\hline T13 & 1.01 & $\mathrm{~T} 33$ & 1.01 & $\mathrm{~T} 53$ & 1.00 \\
\hline T14 & 1.01 & T34 & 0.90 & T54 & 0.90 \\
\hline $\mathrm{T} 15$ & 1.01 & T35 & 0.90 & T55 & 0.90 \\
\hline T19 & 1.02 & T39 & 0.90 & & \\
\hline T20 & 1.01 & T40 & 0.90 & & \\
\hline
\end{tabular}

Table 4: Optimum real power loss values obtained for practical 191 utility (Indian) system by RABC method.

\begin{tabular}{ll|l}
\hline $\begin{array}{l}\text { Real power Loss } \\
(\text { MW) }\end{array}$ & RABC \\
\hline Min & 143.786 \\
\hline Max & 146.982 \\
\hline Average & 144.004 \\
\hline
\end{tabular}

\section{Conclusion}

In this paper, Refined $\mathrm{ABC}$ algorithm (RABC) has been productively implemented to solve reactive power problem. Proposed Refined ABC algorithm (RABC) successfully handles the equality and inequality constraints. The validity of the Refined ABC algorithm (RABC) has been proved by testing it in standard IEEE 118 \& practical 191 test bus systems. The results are compared with the other heuristic methods and the Refined ABC algorithm (RABC) established its efficiency and strength in minimization of real power loss. And voltage profile index are well within specified limits. 


\section{References}

[1] O.Alsac, and B. Scott, "Optimal load flow with steady state security", IEEE Transaction. PAS 1973, pp. 745-751.

[2] Lee K Y ,Paru Y M , Oritz J L -A united approach to optimal real and reactive power dispatch , IEEE Transactions on power Apparatus and systems 1985: PAS-104 : 1147-1153

[3] A.Monticelli , M .V.F Pereira ,and S. Granville , "Security constrained optimal power flow with post contingency corrective rescheduling", IEEE Transactions on Power Systems :PWRS-2, No. 1, pp.175-182.,1987.

[4] DeebN, Shahidehpur S.M, Linear reactive power optimization in a large power network using the decomposition approach. IEEE Transactions on power system 1990: 5(2) : 428-435

[5] E. Hobson ,'Network consrained reactive power control using linear programming, ' IEEE Transactions on power systems PAS -99 (4) ,pp 868=877, 1980

[6] K.Y Lee, Y.M Park, and J.L Oritz, "Fuel -cost optimization for both real and reactive power dispatches", IEE Proc; 131C, (3), pp.85-93.

[7] M.K. Mangoli, and K.Y. Lee, "Optimal real and reactive power control using linear programming”, Electric Power Syst.Res, Vol.26, pp.1-10, 1993.

[8] C.A. Canizares, A.C.Z.de Souza and V.H. Quintana, "Comparison of performance indices for detection of proximity to voltage collapse," vol. 11. no.3, pp.1441-1450, Aug 1996.

[9] S.R.Paranjothi, and K.Anburaja, "Optimal power flow using refined genetic algorithm", Electr. Power Compon.Syst, Vol. 30, 1055-1063, 2002.

[10] D. Devaraj, and B. Yeganarayana, "Genetic algorithm based optimal power flow for security enhancement", IEE proc-Generation.Transmission and. Distribution; 152, 6 November 2005.

[11] Berizzi, C. Bovo, M. Merlo, and M. Delfanti, "A ga approach to compare orpf objective functions including secondary voltage regulation," Electric Power Systems Research, vol. 84, no. 1, pp. 187 $-194,2012$.

[12] C.-F. Yang, G. G. Lai, C.-H. Lee, C.-T. Su, and G. W. Chang, "Optimal setting of reactive compensation devices with an improved voltage stability index for voltage stability enhancement," International Journal of Electrical Power and Energy Systems, vol. 37, no. 1, pp. $50-57,2012$.

[13] P. Roy, S. Ghoshal, and S. Thakur, "Optimal var control for improvements in voltage profiles and for real power loss minimization using biogeography based optimization," International Journal of Electrical Power and Energy Systems, vol. 43, no. 1, pp. 830 - 838, 2012.

[14] B. Venkatesh, G. Sadasivam, and M. Khan, "A new optimal reactive power scheduling method for loss minimization and voltage stability margin maximization using successive multi-objective fuzzy lp technique," IEEE Transactions on Power Systems, vol. 15, no. 2, pp. 844 - 851, may 2000.

[15] W. Yan, S. Lu, and D. Yu, "A novel optimal reactive power dispatch method based on an improved hybrid evolutionary programming technique," IEEE Transactions on Power Systems, vol. 19, no. 2, pp. 913 - 918, may 2004.

[16] W. Yan, F. Liu, C. Chung, and K. Wong, "A hybrid genetic algorithminterior point method for optimal reactive power flow," IEEE Transactions on Power Systems, vol. 21, no. 3, pp. 1163 1169, aug. 2006.

[17] J. Yu, W. Yan, W. Li, C. Chung, and K. Wong, "An unfixed piecewiseoptimal reactive powerflow model and its algorithm for ac-dc systems," IEEE Transactions on Power Systems, vol. 23, no. 1 , pp. $170-176$, feb. 2008.

[18] F. Capitanescu, "Assessing reactive power reserves with respect to operating constraints and voltage stability," IEEE Transactions on Power Systems, vol. 26, no. 4, pp. 2224-2234, nov. 2011. 
[19] Z. Hu, X. Wang, and G. Taylor, "Stochastic optimal reactive power dispatch: Formulation and solution method," International Journal of Electrical Power and Energy Systems, vol. 32, no. 6, pp. $615-621,2010$.

[20] Kargarian, M. Raoofat, and M. Mohammadi, "Probabilistic reactive power procurement in hybrid electricity markets with uncertain loads," Electric Power Systems Research, vol. 82, no. 1, pp. 68 $-80,2012$.

[21] D. Karaboga, "An idea based on honey bee swarm for numerical

[22] Optimization,” Tech. Rep. TR06, Erciyes Univ. Press, Erciyes, 2005.

[23] D. Karaboga and B. Basturk, "A powerful and efficient algorithm fornumerical function optimization: Artificial bee colony (ABC) algorithm," Journal of Global Optimization, Vol. 39, No. 3, pp. 459-471, 2007.

[24] D. Karaboga and B. Basturk, "On the performance of artificial beecolony (ABC) algorithm," Applied Soft computing, Vol. 8, pp. 687-697, 2008.

[25] D. Karaboga and B. Akay, "A comparative study of artificial Beecolony algorithm," Applied Mathematics and Computation, Vol. 214, No. 1, pp. 108-132, 2009.

[26] D. Whitley, “A genetic Algorithm tutorial," Statistics and Computing, Vol. 4, pp. 65-85, 1994.

[27] D. Karaboga and B. Akay, "artificial bee colony (abc) algorithm ontraining artificial neural networks 15th IEEE Signal Processing andCommunications Applications, pp.1-4, 2007.

[28] S. K. Udgata, S. L. Sabat and S. Mini, "Sensor deployment in irregularterrain using artificial bee colony algorithm," IEEE Congress on Nature\& Biologically Inspired Computing, pp. 1309-1314, 2009.

[29] B. Akay and D. Karaboga, "Artificial bee colony algorithm for largescaleproblems and engineering design optimization," Journal ofIntelligent Manufacturing, Vol. 23, No. 4, pp. 1001$1014,2010$.

[30] B. Alatas, "Chaotic bee colony algorithm for global numericaloptimization," Expert Systems with Applications, Vol. 37, pp. 5682-5687, 2010.

[31] G. Zhu and S. Kwong, "Gbest-guided artificial bee colony algorithm fornumerical function optimization," Applied Mathematics andComputation, Vol. 217, pp. 3166-3173, 2010.

Banharnsakun, T. Achalakul and B. Sirinaovakul, "The best-so-farselection in artificial bee colony algorithm," Applied Soft Computing,Vol. 11, No. 2, pp. 2888-2901, 2011.

[32] D. Karaboga and B. Gorkemli, "A combinatorial artificial bee colonyalgorithm for traveling salesman problem," International Symposium onInnovation in Intelligent Systems and Applications (INISTA), pp. 50-53, 2011.

[33] W. GAO and S. Liu, "A modified artificial bee colony algorithm, "Computers \& Operations Research, Vol. 39. pp. 687-697, 2012.

[34] D. Swagatam and P. N. Suganthan, "Differential evolution: a survey ofthe state-of-the-art," IEEE Trans. Evolutionary Computation, Vol. 15, No. 1, 2011.

[35] K. Qin and X. Li, "Differential evolution on the CEC-2013 singleobjectivecontinuous optimization testbed," Proc. of IEEE Congress onEvolutionary Computation, Cancun, Mexico, pp. 1099-1106, 2013.

[36] C. Stephen, M. James and B. R. Antonio, "Standard Particle SwarmOptimization on the CEC2013 Real-Parameter OptimizationBenchmark Functions," Tech. Rep., School of Information Technology, York University, 2013.

[37] IEEE, "The IEEE 30-bus test system and the IEEE 118-test system", (1993), http://www.ee.washington.edu/trsearch/pstca/.

[38] Jiangtao Cao, Fuli Wang and Ping Li, "An Improved Biogeography-based Optimization Algorithm for Optimal Reactive Power Flow", International Journal of Control and Automation Vol.7, No.3 (2014), pp.161-176.

*Corresponding author.

E-mail address: gklenin@ gmail.com 